\title{
Rainfall Variability and Adaptation of Tomatoes Farmers in Santa: Northwest Region of Cameroon
}

\author{
Majoumo Christelle Malyse
}

\section{Contents}

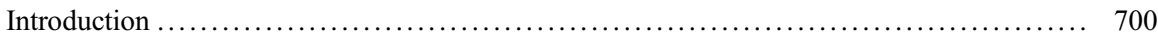

Location of the Study and Research Methodology .............................. 702

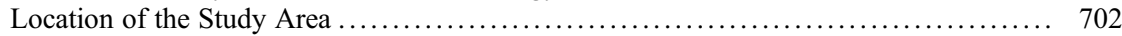

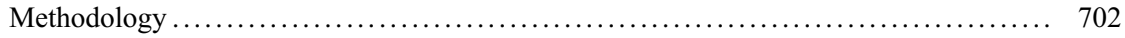

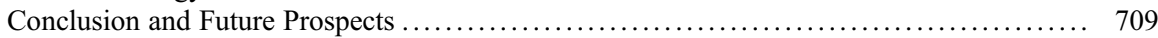

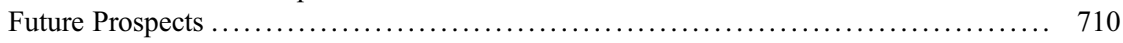

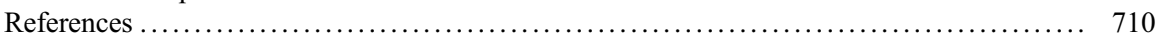

\section{Abstract}

The Santa agrarian basin being one of the main market gardening basins in Cameroon and one of the producers of tomatoes in the country is vulnerable to the impact of rainfall variability. The spatiotemporal variability of rainfall through the annual, monthly, and daily fluctuations has greatly affected the market gardening sector in general and tomatoes production in particular. Thus, given rise to the research topic "Rainfall variability and adaptation of tomatoes farmers in Santa North west region of Cameroon," its principal objective is to contribute to better understanding of the recent changes occurring in tomatoes production and productivity in Santa. To attain this objective, a principal hypothesis was formulated that rainfall variability instead of unnatural conditions or human constraints justifies changes observed in tomatoes production in Santa and resulting adaptation strategies developed by peasants and stakeholders.

This chapter was previously published non-open access with exclusive rights reserved by the Publisher. It has been changed retrospectively to open access under a CC BY 4.0 license and the copyright holder is "The Author(s)". For further details, please see the license information at the end of the chapter.

M. C. Malyse ( $\triangle)$

Department of Geography, University of Dschang, Dschang, Cameroon

e-mail: majounachristelle@gmail.com 
Our study came out with several findings, among which includes rainfall events in Santa fluctuate in time and in space with reduction in the number of rainy day and increase in the intensity of rainfall events causing soil erosion, infertility, and frequent crop diseases, insects, and pests. Extreme events such as drought and flooding have equally become frequent in the area especially during the different cycles of tomatoes production disrupting the agricultural calendar and causing crop failure and decrease in yields with Pearson's correlation of 0.017. This positive value shows that there is a relationship between annual rainfall and tomatoes output in Santa. Tomatoes farmers in Santa are struggling to adapt locally to this situations, but their efforts are still limited especially due to their low level of education and poverty. Finally, it was seen that the output of tomatoes over the years in Santa has a strong correlation with rainfall. Based on the findings of this study, the government is called upon to assist farmers in their adaptation options.

\section{Keywords}

Rainfall variability $\cdot$ Tomatoes production $\cdot$ Extreme events $\cdot$ Santa agrarian basin $\cdot$ Market gardening

\section{Introduction}

The change in global climate system is now undeniable, and it is human-induced as it has been concluded to a large extent by scientists during the past decade (IPCC 2007). Climate variability in general and rainfall variability in particular are very important environmental problems affecting mankind today with the highland areas being very sensitive to the change in rainfall pattern and its related impacts. Tsalefac (1999) in his work on climate variability in the western highlands of Cameroon brought out some aspects. He studied the relationship that exists between climate variability, land-use pattern, and the economic crisis that brings into question the sustainability of land use in the region. As such, this work explores the state of rainfall variability in Santa and some of the adaptation options adopted by tomatoes farmers in Santa. It's aim is to elucidate how changing rainfall pattern in space and in time as well as an increase in extreme weather events which includes dry spells, torrential rains, flooding, and droughts, which has greatly affected tomatoes yields, incidence of weeds, insects, pest and diseases, the economic cost of tomatoes production and how farmers are struggling to adapt to these changes?. This work analyzes tomatoes yields with production cost from 2001 to 2011 with efforts to understand how they have varied with the current rainfall changes. It focuses on extreme weather events on tomatoes production in Santa using examples from recent past such as severe drought of 1999 and 2004 that greatly disrupted the agricultural calendar. Finally, with the current rainfall and tomatoes scenarios serving as models, this work looks at better adaptation options 
that could limit the impact of rainfall variability on tomatoes production and boast tomatoes production in Santa.

The study of Zorom et al. (2013) and Rodriguez Solorzano (2014) on climate variability and adaptation practices by farmers shows the adoption of numerous adaptation strategies to cope with drought conditions. Some of the strategies adopted included the diversification of nonfarm activities such as selling of poultry and rearing of livestock as alternative measures as well as the reduction of food intake. Again, some farmers also engage in the cultivation of dry season irrigated vegetables. They further argued that these practices help farmers to distribute climate risk over different activities which strengthen their financial capacities to be able to raise their purchasing power.

These adaptation strategies adopted by tomatoes farmers in Santa range from changing production techniques to the adoption of improved tomatoes species, irrigation, and the use of agrochemicals and the diversification of activities. Stakeholders' adaptation ranges from the provision of agrochemicals to farmers finance to the provision of farm tools and farm equipment to farmers to help them improve on their production.

Tomatoes production which is a major market gardening crop in Santa has been witnessing a change in the daily, monthly, and annual rainfall in the area.

Variation in the date of onset, amounts, and the retreat of rainfall has affected the growth of tomatoes over the years.

However, the inability of tomatoes farmers to master and cope with rainfall especially the coming of rains has been a major setback to current and future tomatoes production as according to most of the peasants, rainy season during the past years has been very fluctuating and does not begin in mid-March as in the past years; rather, it begins in February and at times comes late and most of the time very is irregular, making the availability of water for irrigation very difficult. The few streams and watershed whose water up wells the water needed by plants are vast declining in quantity; this has been a natural occurrence, and these farmers and their crops have an average chance of survival. They loss income, time, and crops.

Dry spells as well as rainy days recorded on this area have been responsible for the outbreak of diseases such as septoria leaf spot, anthracnose, and Verticillium which leads to a fall in yields. This is particularly worrisome because farmers have very little strategies as they have resorted in the use of pesticides which has both negative and positive impacts on both the plant and the environment. Most of the time, pesticides are being washed away by heavy downpour due to the fact that most farmers do not know the best times to apply these pesticides. Heavy downpours have led to rapid depletion of the soils in some areas which have completely destroyed large portions of lands with crops. With all these, farmers in Santa have tried to make up for this loss by augmenting the dosage of fertilizers to beef up growth and productivity, but these fertilizers are very bad for the longevity of crops. Looking on the above explanations, the following question will guide us throughout this work: How does rainfall impact tomatoes farming in Santa? What are the farmers doing to remedy the situation? 


\section{Location of the Study and Research Methodology}

\section{Location of the Study Area}

Santa is one of the 32 subdivisions in the northwest region located between latitude $5^{\circ} 42 \mathrm{~N}$ to $5^{\circ} 53 \mathrm{~N}$ of the equator and longitude $9^{\circ} 58 \mathrm{E}$ to $10^{\circ} 18 \mathrm{E}$ of the Greenwich meridian. It falls within the western highlands agroecological zone and covers a surface area of about 532,67 $\mathrm{km}^{2}$. It covers some villages, namely, Akum, Baba II, Pinyin, Baligham, Matazem, and Santa (Njong, Ntarrah, and Mbei), which are our zone of study. This area lies some $20 \mathrm{~km}$ from Bamenda and is commonly called "the gateway into the northwest region" with an altitude from 1000 to $2600 \mathrm{~m}$, making the area suitable for the cultivation of market garden crops especially tomatoes (Fig. 1).

\section{Methodology}

\section{Data Collection}

Primary data was collected from key informant such as tomatoes farmer, agricultural extension officers (MINADER and ACEFA), and field officers of research institutes (IRAD). This information was obtained through observations, interviews, and questionnaires. Field observation was very important in making a correlation of questionnaire response by the farmers to the actual remarkable activities in the farm. Field visits were made at different tomatoes farming sites in Santa where different farming, impacts of rainfall variability on tomatoes plants, and adaptation practice were applied with the help of some main tomatoes farmers. A total of 100 questionnaires were taken to the different selected villages, of which 39 were distributed in Ntarrah, 22 in Njong, and 39 in Mbei. Interviews were equally conducted with Farmers in the area who knew the area and had experience in tomatoes production. However, rainfall and output data was equally a secondary data of this study, of which the rainfall data here was obtained from two meteorological stations: Santa and Bamenda stations. The rainfall data used in the study ranged from 1963 to 2011 for the Bamenda station and from 1981 to 2006 for the Santa station. The different quantity of tomatoes harvested by farmers between the years 2001 and 2011 was obtained from the subdivisional delegation of agriculture for Santa and was used hand in globe with the rainfall data to show how rainfall variability has impacted on tomatoes production output over the years in Santa.

\section{Presentation of Results and Discussions}

The state of rainfall variability in Santa is analyzed based on the interannual and monthly anomalies as well as variability in rainfall intensity and rainy days which has really show evidence of rainfall variability in Santa this has greatly impacted 


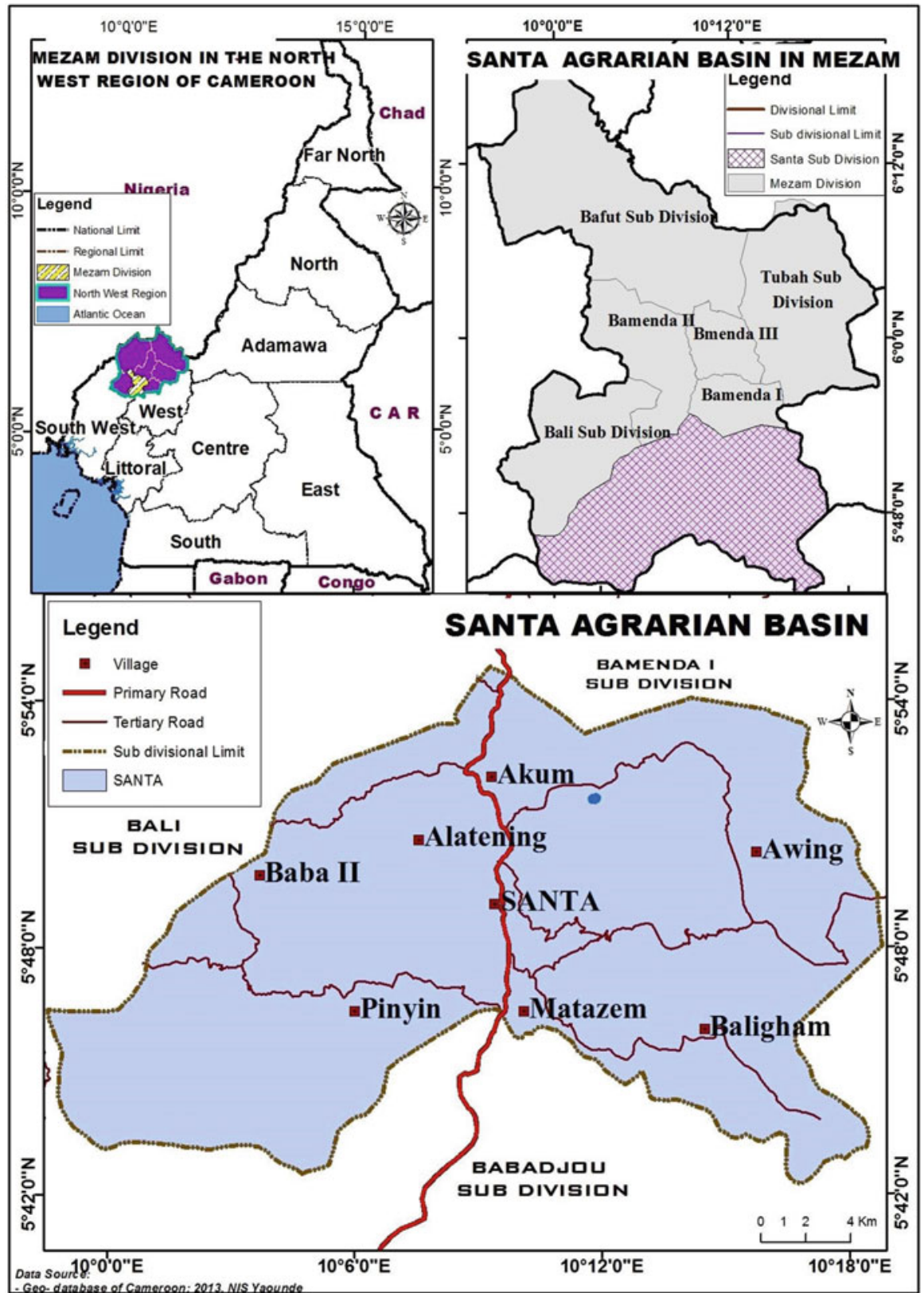

Fig. 1 Location and layout of the Santa agrarian Basin. (Source: Extracted from Fogwe and Zoum 2014) 
tomatoes production in different ways which includes the attack of tomatoes crops by diseases, insects and pest, soil erosion causing infertility of soils, inaccessibility, water shortages most farmers have come out with several adaptation strategies to adapt to the impact of rainfall variability in Santa which has greatly decrease the yields of farmers.

\section{State of Rainfall Variability in Santa}

\section{Interannual Anomalies in Santa}

The situation in Santa demonstrates more negative anomalies than positive anomalies as seen.

Figure 2 shows rainfall anomalies in Santa. As already mentioned, years with positive anomalies are fewer than years with negative anomalies. The few years that registered rainfall over the annual average for the periods were 1990, 1992, 1997, 2001, 2002, and 2003. On the other hand, most years had rainfall lesser than the annual average such as the period from 1981 to 1989,1993 to 1996,1998 to 2000 , and 2004 to 2006. Within these years of less rainfall, the period 2004 to 2006 stands out exceptionally and indicates dry periods.

\section{Rainfall Variability in Santa}

The variability of rainfall equally manifests on monthly basis. Generally, the monthly rainfall pattern affects the seasonal pattern. This area falls within the humid tropical climate with two distinct seasons, a short dry season and a long rainy season. Dry season months record lower rainfall amounts than rainy season months in both Santa and Bamenda stations. Tomatoes production in Santa depends on the pattern of rainfall as it provides water and moisture for plant growth.

Figures 3 and 4 indicate that rainfall is lower for the months of January, February, November, and December. These months are the dry season months. The amounts begin to rise from March which marks the beginning of the rainy season, and the

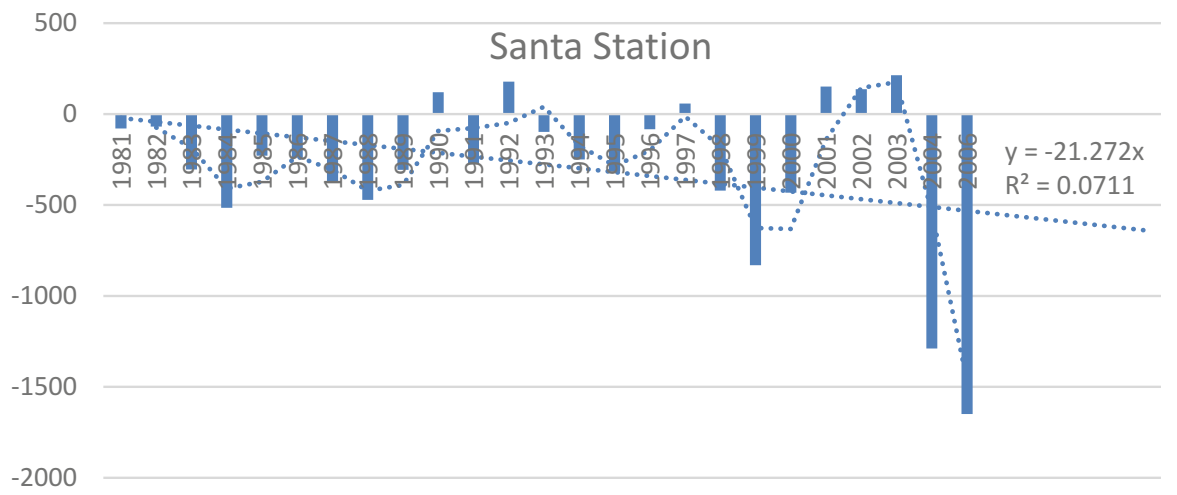

Fig. 2 Interannual anomalies 
Fig. 3 Monthly rainfall variability in Santa station
Fig. 4 Monthly rainfall variability in Bamenda station
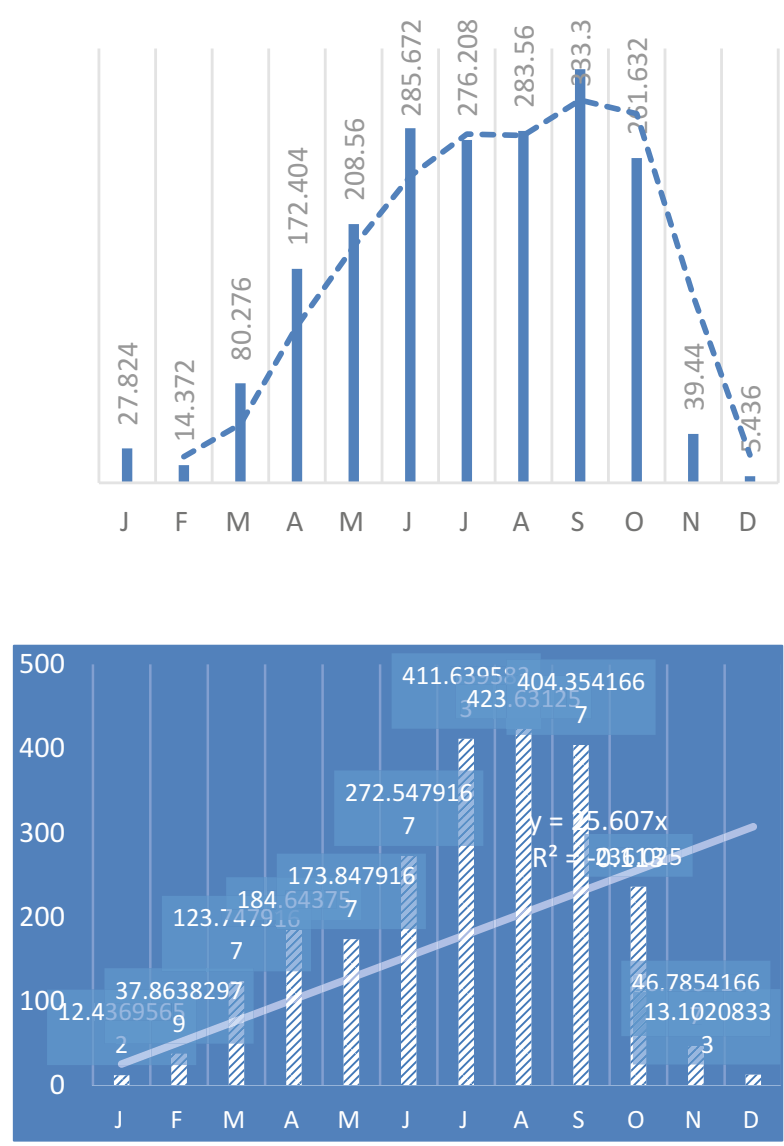

highest amounts are registered in the months of June, July, and August. These months are at the mid of the rainy season.

This trend is the same for both stations, but there is an indication of spatial variability when referring to the two stations. It is observed that rainfall amounts vary within the same months in both stations.

\section{Variability in the Number of Rainy Days and Rainfall Intensity}

Variation in the number of rainy days and changes in rainfall intensity are some powerful indicators of rainfall variability. This change has a link with fluctuations in the dates of onset and departure of rains. Generally, a rainy day refers to a day that records at least $1 \mathrm{~mm}$ of rainfall. The number of rainy days varies according to seasons, but when observed annually, we noticed the days have been fluctuating over the past years in Santa.

Figure 5 shows variability in rainy days from 1963 to 2011 in Santa. The highest number of rainy days was recorded in 1999 (225 days), 1976 (222 days), and 2002 


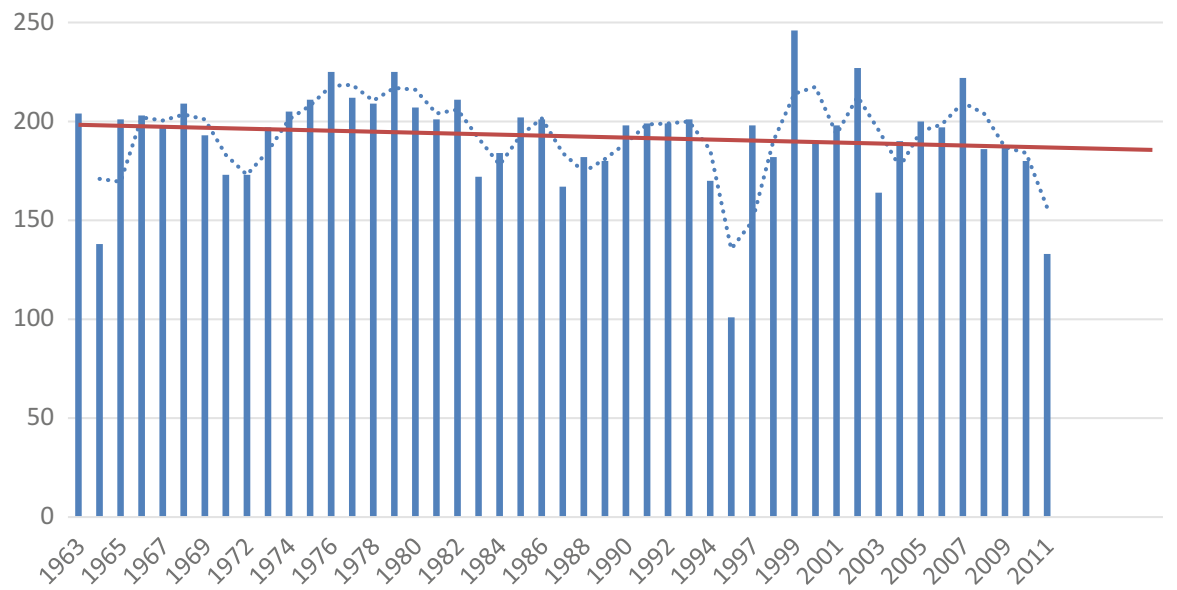

Fig. 5 Interannual fluctuation in rainy days in Santa. (Source: Fieldwork 2018)

Table 1 Farm-level adaptation strategies

\begin{tabular}{l|l|l|l}
\hline & Variables & Frequency & Percentages \\
\hline 1 & Crop diversification & 17 & 17.34 \\
\hline 2 & Use of agrochemicals & 54 & 55.10 \\
\hline 3 & Mixed cropping & 4 & 4.08 \\
\hline 4 & Irrigation farming & 13 & 13.26 \\
\hline 5 & Changing crop varieties & 10 & 10.20 \\
\hline & Total & 98 & 100 \\
\hline
\end{tabular}

Source: Fieldwork 2018

(207 days). On the other hand, 1964, 1995, and 2011 had the least number of rainy days (138 days, 101 days, and 133 days, respectively). The annual difference in rainy days is about 124 days which is very large. This is an indicator of rainfall variability because it affects the frequency and intensity of rainfall.

\section{Peasant Adaptation to Rainfall Variability on Tomatoes Production in}

\section{Santa}

Peasants in Santa have adopted several adaptation options to reduce the impact of rainfall variability on tomatoes production. These impacts are numerous, and the capacity to adopt varies according to farmers and the farm sizes. These adaptation options can be classified into two groups: the farm-level adaptation options and the nonfarm-level adaptation options (Table 1).

Tomatoes farmers in Santa use the farm-level adaptation options such as the use of new species of tomatoes, pesticides, and agrochemicals, changing farming 
Photo 1 Improved variety of tomatoes (F-hybrid species). (Source: Photo by Majoumo 2018)

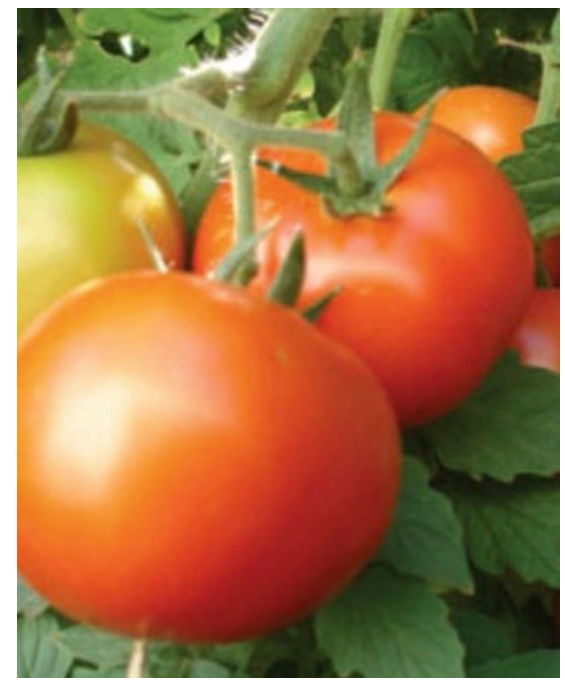

methods, and irrigation methods in order to reduce the impact of rainfall variability on their tomatoes farms.

\section{Adaptation to Improved Varieties of Tomatoes}

The use of improved varieties of tomatoes by most farmers in Santa has been a major response to drought and pest. The new variety used by farmers in this area is the F1hybrid. According to one of the farmers interviewed (Photo 1):

Hybrids are plants that are a result of cross pollination and they have advantages compared to open pollinated varieties they mature earlier and are uniformly than the other species and are resistant to change in seasons and diseases. (NGU 2018)

\section{Adaptation Through Irrigation}

Irrigation is one of the major adaptive strategies that could improve tomatoes yields in era of climate variability (Olwoch and Tshiala 2010). Tomatoes are not resistant to drought. Yields decrease considerably after the short period of water deficiency. It is important to water the plants regularly during flowering and fruit formation. The amount of water that is needed depends on the type of soils. Irrigation is one of the adaptive measures used by famers in Santa during periods of drought and low rainfall. Some of the different irrigation methods used by farmers in Santa on their farms includes the use of water pipes and watering canes to obtain water from wells to water farms, as can be seen in Plate 1.

From Plate 1, Photo 1 shows the sprinkler irrigation method used by tomatoes farmers in Santa to irrigate their farms during period of no rainfall or prolonged dry season, Photo 2 shows the water pipes used by farmers to connect water into their 


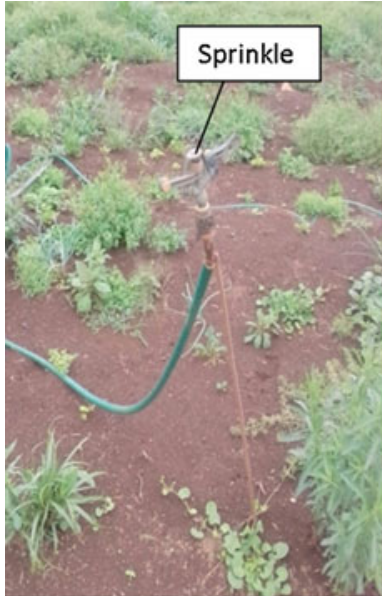

PHOTO 1

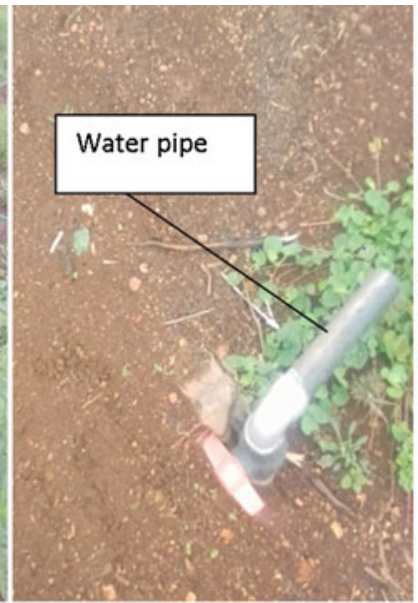

PHOTO 2

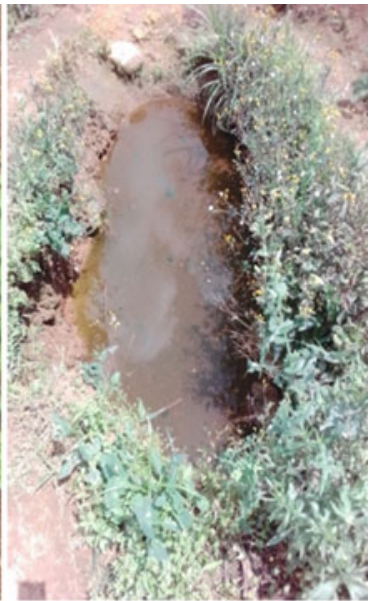

PHOTO 3

Plate 1 The different methods of irrigation used by tomatoes farmers in Santa

farms, and Photo 3 shows another local way of irrigation where farmers dig holes where there is water and use watering canes to carry water to water their farms.

\section{Cropping System and Change in the Technique of Production as an Adaptation Option}

Most farmers in Santa use poor farming methods to cultivate their crops which has greatly reduced their yields and also makes the area vulnerable to extreme climatic conditions such as flooding, droughts, as well as soil erosion. Tomatoes farmers in Santa are moving from monoculture to mixed cropping, crop rotation, and intercropping to avoid the risk of reduction in yields as well as crop failure and to equally allow the soils to regain its fertility. It was observed that tomatoes farmers in Santa mix tomatoes with crops such as green beans and lettuce and most of them do carry out intercropping on tomatoes farms.

\section{Adaptation Through the Use of Agrochemicals and Fertilizers}

The application of agrochemicals and fertilizers is common to all tomatoes farmers in Santa. The application of agrochemicals and fertilizers improves soil fertility and eradicates crop diseases, insects, and pests. Also, the use of agrochemicals especially fertilizer is a good adaptation strategy that improves tomatoes yields (Tshiala and Olwoch 2010). Most of the farmers in this area apply the NPK 20:10:10 fertilizer in order to increase fertility of their soils especially soils that have been rendered fertile during heavy rainfall or changing rainfall. With the growth of diseases and pest in Santa that affect tomatoes crops, most farmers adapt to use agrochemicals for their crops. An example of pesticide used by farmers in Santa is the CLEANZEB BLUE. 
Table 2 Nonfarm-level adaptation

\begin{tabular}{l|l|l|l}
\hline & Variables & Frequency & Percentages \\
\hline 1 & Diversification of nonfarm activities & 45 & 45.91 \\
\hline 2 & Migration & 53 & 54.08 \\
\hline & Total & 98 & 100 \\
\hline
\end{tabular}

Source: Fieldwork 2018

\section{Diversification to Off-Farm and Nonfarm-Level Activity Adaptation Strategies}

Diversification to nonfarm and off-farm activities is one of the adaptive measures that is not popular to tomatoes farmers in Santa, but it was much preferred by most them as it was seen that most of the farmers in that area do carry out other activities such as trading, bike riding, and dress making, just to name a few. Some of these farmers even migrate to other areas in search of jobs especially in urban centers as shown in Table 2.

Table 2 shows the different off-farm adaptation options adopted by farmers in Santa. $54.08 \%$ of farmers say they diversify into nonfarm activities such as trading, teaching, and bike riding, just to name a few, while $45.91 \%$ migrate to other areas to obtain lands that are more fertile and to areas they think do not suffer from extreme weather conditions or in search for jobs. Respondent explained that the tomatoes business is the main source of livelihood bequeathed to them by their forefathers.

\section{Conclusion and Future Prospects}

This study has been able to come out with the state of rainfall variability on tomatoes production in Santa and some of the adaptation options adopted by farmers to remedy the situation. Rainfall events in Santa fluctuate seriously around the mean values. Data from two meteorological stations were analyzed and show yearly, monthly, and daily rainfall variability.

Spatial rainfall variability in the area shows that rainfall has become intense and fall over short duration varying from one area to another. This was analyzed in this work due to the fact that data for this study was obtained from two stations found on the same geographical locations. Temporally, as years goes by, rainfall is becoming very unreliable and varies greatly within the same months.

Extreme weather events such as heavy rains, drought, and flooding are increasingly becoming common in Santa, their occurrence determines the length of growing period, distorts the plants through diseases insects and pest during the plants life cycle, soil lost through flooding and erosion is one of the characteristics of rainy seasons in this area. Most of the farmers in the area are becoming aware of the situation as they have perceived the presence of rainfall variability in the area through the different ways in which it manifest.

In order to adapt to the situation, most of the farmers resorted in the use of irrigation, agrochemicals, mixed cropping, and diversification in nonfarm activities which have greatly helped them to improve on their productivity over the past years. 


\section{Future Prospects}

The introduction of various adaptation strategies by the government and/or stakeholders, including the method of distribution of the agricultural inputs, was found to be very uncertain and partly unacceptable by most farmers in the study area. Thus, there is a need of further studies in this area to explore and develop the best method that will be efficient and effective.

Furthermore, an improvement in agricultural research will provide a backbone for adaptation measures. This is because research rapidly changing situations is different from research for stable conditions. Therefore, traditional knowledge is a suitable entry point but very insufficient in a changing situation. So tomatoes varieties need to be developed for future conditions as their applicability cannot be assessed at the location where they may be used in the future. The results of the research have to be published in an environment in which methods and crop varieties are accessible for use.

The analysis of the effect of rainfall variability on tomatoes production indicates that farmers do face production losses since the study area is vulnerable to rainfall and tomatoes production and tomatoes are one of the market gardening crops mostly cultivated by farmers in Santa. It is very important to develop a drought-resistant tomatoes variety that can withstand drought and extreme weather conditions and help to improve yields. It is therefore imperative that institutes such as crop research institutes like IRAD in the country develop more resistant drought varieties to withstand extreme weather conditions.

\section{References}

Fogwe ZN, Zoum BC (2014) Perception and adaptation ajustements to climate variability by Farmers within thé Santa agrarian Basin, 27-31pp.

IPCC (2007) The fouth assessment report

Olwoch JM, Freddy TM (2010) Thé impact of climate change and vraiblility on tomatoes production in thé limpopo province South Africa, 88-99pp

Rodriguez S, C. (2014) Unintended outcomes of farmers' adaptation to climate variability: deforestation and conservation in Calakmul and Maya biosphere reserves. Ecology and Society. Vol. 19, No $2,2 \mathrm{pp}$

Tsalefac M (1999) Variabilité climatique, crise économique et dynamique des milieux agraire sur les Haute terres de l'ouest Cameroun. Thèse de Doctorat d'Etat de lettre et the science humaine, spécialité, option climatologie, Université de Yaoundé, 564p

Tshiala MF, Olwoch JM (2010) Impact of climate variability on tomato production in Limpopo province, South Africa. Afr J Agric RES. 13-20p

Zorom M, Barbier B, Mertz O, Servat E (2013) Diversification and adaptation strategies to climate variability: a farm typology for the Sahel. Agric Syst 116:7-15 
Open Access This chapter is licensed under the terms of the Creative Commons Attribution 4.0 International License (http://creativecommons.org/licenses/by/4.0/), which permits use, sharing, adaptation, distribution and reproduction in any medium or format, as long as you give appropriate credit to the original author(s) and the source, provide a link to the Creative Commons license and indicate if changes were made.

The images or other third party material in this chapter are included in the chapter's Creative Commons license, unless indicated otherwise in a credit line to the material. If material is not included in the chapter's Creative Commons license and your intended use is not permitted by statutory regulation or exceeds the permitted use, you will need to obtain permission directly from the copyright holder.

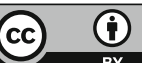

